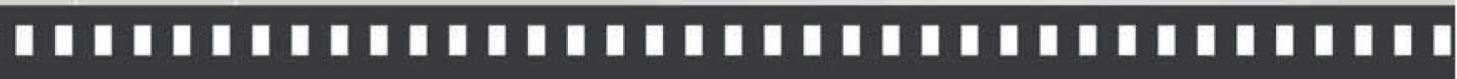
Por Trás Das Câmeras: A Decupagem Cinematográfica Como Inscrição Discursiva

I I I I I I I I I I I I I I I I I I I I I I I I I I I I D

\author{
João Flávio Almeida \\ Dantielli Assumpção Garcia \\ Lucília M. A. e Sousa \\ Maria Beatriz Ribeiro Prandi \\ Artigo recebido em: 08/09/2015 \\ Artigo aprovado em: 06/05/2016
}




\title{
Por Trás Das Câmeras: A Decupagem Cinematográfica Como Inscrição Discursiva
}

\section{Behind The Cameras: Cinematic Decoupage As Discursive Registration}

\author{
* João Flávio Almeida, ** Dantielli Assumpção Garcia, \\ *** Lucília M. A. e Sousa, e *****Maria Beatriz Ribeiro Prandi
}

Resumo: Sob o arcabouço teórico da Análise do Discurso Francesa, inaugurada por Michel Pêcheux, buscaremos neste artigo discutir o papel da imagem em movimento -o cinema - na produção de sentidos no discurso. Uma película cinematográfica movimenta sentidos através de diversas formas, ora verbais, ora não-verbais; e, neste artigo, temos por objetivo mirar aquilo que é dito em forma de sequências de imagens, ou seja, observar a própria estrutura constituinte do fazer cinematográfico como ferramenta de inscrição discursiva.

Palavras-chave: Análise do Discurso, Cinema, Imagem, Ideologia.

Abstract: Under the theoretical framework of the French Discourse Analysis, inaugurated by Michel Pêcheux, we will seek in this article a discussion about the role of the moving image - the cinema - in the creation of meaning in speech. A motion picture film moves senses through various forms, sometimes verbal, sometimes nonverbal; and in this article we aim to target what is said in the form of image sequences, i.e. to observe the very constitutional structure of filmmaking as a tool of discursive inscription.

Keywords: Discourse Analysis, Film, Image, Ideology.

\footnotetext{
* Universidade Federal de São Carlos (UFSCar).

** Universidade de São Paulo (USP).

*** Universidade de São Paulo (USP).

**** Universidade de São Paulo (USP).
} 


\section{Introdução: os jogos de linguagem da decupagem cinematográfica}

A imagem em movimento possui uma matéria visual muito específica que a faz única enquanto materialidade discursiva. Ela permite trabalhar o verbal e o não-verbal simultaneamente, restituindo à materialidade da linguagem sua complexidade e multiplicidade (ORLANDI, 1997). O exame da imagem cinematográfica traz em si um conflito enunciativo entre o que se vê na superfície, na materialidade verbal e não-verbal, e o que lhe está calado, opaco, mas que, por meio de uma análise discursiva, é possível perceber seu funcionamento histórico e ideológico. Seu caráter de reprodução fiel e exata de mundo faz parecer que o que a imagem diz é exatamente aquilo que é, tal como o processo de esquecimento enunciativo (PÊCHEUX; FUCHS, 1997), que apaga ambiguidades e derivas na construção dos sentidos e faz "esquecer" que existem outras formas de se significar algo. No caso do cinema, este esquecimento é o que desambiguiza outros sentidos que não aqueles enquadrados pela câmera. Como aponta Pêcheux e Fuchs (1997, p. 161), no esquecimento de ordem enunciativa (esquecimento número dois), o sujeito-falante:

"seleciona" no interior da formação discursiva que
o domina, isto é, no sistema de enunciados, formas
e sequências que nela se encontram em relação de
paráfrase - um enunciado, forma ou sequência, e não
um outro, que, no entanto, está no campo daquilo que
poderia reformulá-lo na formação discursiva considerada.

Assim, para entendermos como um filme faz sentido, será necessário buscar suas regularidades não em seus produtos, mas sim em seus processos de produção (PÊCHEUX; FUCHS, 1997), isto é, ao analisarmos um filme, buscamos perceber como, pelas 
escolhas de enquadramentos, falas, músicas, jogos de planos, luz e cores alguns dizeres são ditos e outros apagados, sempre produzindo significação.

Em relação aos processos de produção do discurso imagético (cinematográfico), tomaremos como ponto de partida a obra de Ismail Xavier (2005) intitulada “O Discurso Cinematográfico: a opacidade e a transparência". O autor apresenta uma análise dos mecanismos de comunicação do cinema e, desde o início, traz conceitos que propomos, neste artigo, aproximar da teoria pechetiana. Já em seu título se faz menção a discurso, opacidade e transparência, termos recorrentes e importantes dentro da Análise do Discurso Francesa. Desse modo, o objetivo secundário deste artigo será aproximar os conceitos de Xavier, quando analisa a materialidade discursiva "cinema", dos conceitos pechetianos de análise discursiva. Esse percurso se justifica em virtude do objetivo primário deste artigo: examinar os processos de produção de um filme na intenção de captar como a decupagem, a filmagem, a montagem e outros, dotados de opacidade (por oposição à transparência, esta almejada por algumas correntes cinematográficas), revelam importantes enunciados silenciados justamente porque esse ferramental constitutivo do cinema deve se manter fora da cena, por trás das câmeras, invisível justamente para que o filme se constitua enquanto filme. Enquanto fala, a decupagem deve, ao mesmo tempo, tornar invisível seu próprio processo enunciativo, como veremos adiante.

\section{Pêcheux e Xavier: aproximações teóricas}

Nesta etapa do artigo, propomos aproximações conceituais entre os dois autores no que cinge "Condições de Produção" de dizeres (PÊCHEUX; FUCHS, 1997), no caso, dizeres cinematográficos. Essa aproximação será feita com cuidado, assumindo o caráter introdutório de tal conceituação. Um dos conceitos que aparecem em ambos e que permite, ao menos inicialmente, observarmos os processos de produção de um filme por meio de uma leitura 
discursiva é o conceito de ideologia. Vale ressaltar que tal conceito, como desenvolve Xavier, não implica uma relação mútua com o conceito de sujeito; diferentemente de Pêcheux, em que estes conceitos se imbricam numa mútua constituição.

Pêcheux parte da noção marxista de ideologia, pelas mãos de Althusser, para observar as relações que permeiam toda produção cultural humana; melhor dizendo, a ideologia é o mecanismo que produz as evidências que colocam o homem numa relação imaginária de verdade com a história e a sociedade; um movimento que se dá concomitantemente à própria dissimulação:

o caráter comum das estruturas-funcionamentos
designadas, respectivamente, como ideologia e
inconsciente é o de dissimular sua própria existência no
interior mesmo de seu funcionamento, produzindo um
tecido de evidências "subjetivas", devendo entender-se
este último adjetivo não como "que afetam o sujeito", mas
"nas quais seconstitui o sujeito"(PÊCHEUX, 1995,p.152).

Neste aspecto, Pêcheux se atenta em distinguir Ideologia (no singular) de Ideologias (Formações Ideológicas), e também de Ideologia dominante. Ele afirma que a realização da ideologia, em geral, "não se dá, como vimos, nos aparelhos ideológicos de Estado - de modo que ela não poderia coincidir com uma formação ideológica historicamente concreta - não é também a ideologia dominante" (IDEM, p. 151). Enquanto as Ideologias possuem uma história própria, por possuírem uma existência histórica e concreta, a Ideologia não tem história, na medida em que ela se caracteriza por

uma estrutura e um funcionamento tais que fazem dela uma realidade não-histórica, omni-história, no sentido em que esta estrutura e este funcionamento se apresentam na mesma forma imutável em toda 
história, no sentido em que o Manifesto define a história como história da luta de classes (IDEM, p. 152).

Mas não existiria ideologia sem sujeito: "só há prática através de e sob uma ideologia", e "só há ideologia pelo sujeito e para sujeitos" (IDEM, p. 149). Nessa relação conceitual, a constituição do sentido se junta à constituição do sujeito em forma de interpelação. Interpelar, aqui, é como aquele "chamar" autoritário que exige explicações ou impõe certas escolhas e sentidos. Nas palavras de Pêcheux, a interpelação é como aquela convocação que faz a religião ("Ei, você, por quem eu derramei essa gota de sangue!"), e a polícia ("Ei, você aí!”), um assujeitamento que realiza o vínculo entre o Aparelho Repressivo de Estado, que distribui, verifica e controla identidades, e os Aparelhos Ideológicos de Estado, que regulam as relações entre as identidades. (IDEM, p. 154).

Assim, ideologia e inconsciente estão materialmente ligados através da língua. E assim, ao se tomar a ideologia em sua relação com a língua, o discurso e o sujeito, é preciso levar em conta o lugar (material, empírico) que o sujeito ocupa na sociedade como condicionante de seu dizer; e, ao se identificar com determinados dizeres, o sujeito se inscreve/submete numa formação discursiva, o momento em que ele deixa de ser indivíduo empírico e passa a sujeito do discurso. Circunscrito pela ideologia, o sujeito discursivo passa por um processo de "incorporação-dissimulação" dos elementos do interdiscurso constituinte da linguagem. Enquanto toma os saberes constituintes de um determinado espaço ideológico, este funcionamento dissimula a origem do próprio discurso, aparecendo ao sujeito como um dizer já-dado e pronto (PÊCHEUX, 1995), como se a fala coincidisse de fato com a realidade. Contudo tal movimento (incorporar/dissimular), aponta o autor, se dá de forma inconsciente, silenciosa e invisível.

Olhando discursivamente para o "fazer" cinematográfico, Ismail Xavier também discute o conceito de ideologia, ressaltando suas implicações nos processos de produção de um filme. Contudo, 
para avançarmos no delineamento de tais conceitos neste autor, faz-se necessário apontar que tais discussões sobre ideologia, silenciamentos e outros, são mais claramente percebidos naquilo que é conhecido como Cinema Naturalista (também descrito como Ilusionista), sob o ferramental da Decupagem Clássica. Segundo o autor, a representação naturalista é definida por um conjunto de fatores que buscam assegurar ao cinema uma representação mais próxima do "real". Tais fatores podem ser desde o tipo de atuação dos atores, os cenários que buscam imitar o real, uma fotografia naturalista que busca uma iluminação que pareça ser natural - a despeito de todos os artifícios que utiliza para obter essa naturalidade; a direção de arte, que deve fornecer objetos e figurinos que garantam a verossimilhança da estória etc (XAVIER, 2005).

A decupagem clássica, por sua vez, é o conjunto de procedimentos que visa diminuir (e se possível, eliminar) a principal característica do cinema: a descontinuidade. Isso se equipara a um pintor que tentasse apagar os traços do pincel em sua tela, os vestígios de sua criação. Assim, a decupagem clássica, usada no cinema naturalista, busca dissimular os vestígios da produção cinematográfica em seu produto final. Assim, através da montagem retira-se cenas indesejadas, une-se cenas desconexas temporalmente e espacialmente, sincroniza-se som e imagem, repete-se o movimento dos atores fazendo-o parecer único, organiza-se conjuntos de sequências etc (XAVIER, 2005). Em outras palavras, a Decupagem Clássica é o conjunto de recursos que tenta garantir que a ação transcorra sem interrupção, como se os eventos tivessem ocorrido naturalmente, mesmo que para isso o Cinema Naturalista tenha de ocultar a presença dos mecanismos da própria produção. Tal utilização da representação naturalista, somada à Decupagem Clássica, pode ser considerada a gênese do cinema de Hollywood, bem como a grande responsável por sua hegemonia quase mundial.

Para Xavier, o Cinema Naturalista, através da Decupagem 
Clássica, faz com que a ideologia que se materializa no cinema seja silenciosa e invisível; e tal como conceitua Pêcheux, para esse teórico do cinema a ideologia faz trabalhar uma ilusão silenciosa de paridade entre linguagem e realidade, entre o filme e o mundo.

[...] a noção de ideologia é formulada de modo a confundir-se com a percepção (= depósito das ilusões da consciência e lugar da criação de continuidade, teleologia e representações falsas do mundo). Nesse sentido, a teoria da "transparência" [...] é eminentemente reacionária: não é a "realidade concreta" do mundo que é "apreendida" por (ou melhor: que impregna) um instrumento não intervencionista, mas antes o mundo vago, informulado, não teorizado, impensado da ideologia dominante. As linguagens pelas quais o mundo fala (entre elas, o cinema) constituem a sua ideologia, pois, ao se expressar, o mundo aparece tal como é vivido e apreendido, isto é, na chave da ilusão ideológica (XAVIER, 2005, p. 148).

Ao avançar no conceito de ideologia que se manifesta na linguagem cinematográfica, Xavier recorre à diferença entre cinema e literatura, uma vez que em ambos os casos o narrador seleciona o que entra ou não na história, e, por isso mesmo, constitui uma escolha política (XAVIER, 2005). O cinema, afirma Xavier, carrega intrinsicamente um agravante: o de se concretizar através de uma soma de imagens e sons supostamente reais, imersos numa continuidade espaço-temporal que supostamente coincide com a realidade.

Aliás, tal continuidade espaço-temporal é uma das constituições cinematográficas que mais preocupa Xavier, que alerta para a impressionante semelhança entre uma fotografia estática e a realidade (XAVIER, 2005). No instante em que verifica o cinema segundo o olhar da corrente "realista", Xavier assume esse caráter intimidante de verossimilhança da fotografia: a luz que incidiu sobre um determinado objeto, num instante e lugar 
específicos, não afetou nenhum olho humano, mas sim a lente da câmera que a captou e de alguma forma registrou para uma possível revisitação. A fotografia insinua uma realidade tal como realmente (supostamente) é. Xavier aponta, todavia, que o poder realista de uma imagem estática é insignificante se comparado ao realismo da imagem em movimento. Segundo o autor, um filme parte de uma única fotografia através da qual será atribuído um desenvolvimento temporal. Se o realismo da fotografia era já celebrado mesmo sem o atributo do movimento, o cinema toma a "realidade tal como supostamente é" da fotografia, e lhe adiciona temporalidade, uma multiplicação radical do poder de ilusão (XAVIER, 2005, p. 19).

Xavier aponta que certa discussão já tomava forma no início do século XX: o filme, sendo um encadeamento de fotografias, permite uma manipulação tal que uma sequência de fotografias pode ser interrompida e sucedida por outra que não tenha nenhuma relação natural com a primeira. Essa relação entre diferentes sequências é manejada por duas operações básicas do cinema: a filmagem e a montagem. Questões ideológicas já nos surgem: para onde a câmera "olhará" e como o fará? Como as sequências serão combinadas e ritmadas? A preocupação sobre uma possibilidade de manipulação da realidade já rondava os teóricos de então. Nos primórdios do cinema, tais questões chegaram a incidir sobre a produção cinematográfica, e já naquela época a problemática da ética do enquadramento da câmera já rondava estúdio e universidades. A câmera, por possuir um campo de abrangência menor do que o olho humano, oculta coisas enquanto mostra outras, mira uma direção específica voluntariamente, segundo intenções de forma alguma neutras, omitindo outras possibilidades de ver e apreender aquele espaço (XAVIER, 2005).

Ora, o fora (o extra, o esquecido etc) é copiosamente analisado pela AD: os espaços fora dos dizeres, ou seja, aquilo que é omitido também diz, além de dar pistas sobre a filiação ideológica do enunciador. E como são muitos os fora-dizeres, o enunciado escolhido trabalha certa estabilização discursiva. Dessa forma, o 
realismo de uma fotografia - somado aos processos de filmagem e de montagem - constitui nitidamente um universo cinematográfico logicamente estabilizado, um mecanismo de silenciamento e estabilização de um único dizer que o faz parecer único: uma univocidade lógica.

[...] Pois sempre há outros jogos no horizonte [...], mas enquanto tal, seu resultado deriva de um universo logicamente estabilizado (construído por um conjunto relativamente simples de argumentos, de predicados e de relações) que se pode descrever exaustivamente através de uma série de repostas unívocas a questões factuais (PÊCHEUX, 2008, p. 22).

Tal univocidade lógica percebida na filmagem e na montagem novamente faz funcionar o esquecimento número dois, da teoria pechetiana. Trata-se de que, ao se organizar um enunciado, sempre se faz de uma maneira e não de outra, decorrendo uma impressão ilusória de que há uma relação natural e direta entre o pensamento, a linguagem e o mundo, quando na verdade não há (ORLANDI, 2005 , p. 35). O conceito de paráfrase também se desponta na medida em que "o que não está enquadrado" pela câmera diz tanto quanto o que aparece, e é desta relação entre ditos e não-ditos parafrásticos que surge o efeito de sentido.

[...] Para nós, a produção do sentido é estritamente indissociável da relação de paráfrase entre sequências tais que a família parafrástica destas sequências constitui o que se poderia chamar a "matriz do sentido". Isto equivale a dizer que é a partir da relação no interior desta família que se constitui o efeito de sentido (PÊCHEUX E FUCHS, 1997, p. 169).

De fato não há como ser diferente. A câmera não é capaz de 
captar em todas as direções, e, mesmo se o fizesse, ainda haveria limitações espaciais, e, em última instância, até mesmo o horizonte serviria de limite: o olhar humano (assim como a câmera) não é capaz de ver o mundo todo, todo o tempo. O recorte é natural, e o enquadramento, necessário. Para Xavier, o enquadramento é um constante pressuposto: a visão direta de uma parte se refere à presença de um todo que se desdobra para o espaço "fora da tela". O campo enquadrado tende a indicar a própria extensão para fora dos limites do quadro, apontando para um espaço próximo e imediato não visível. Sobre isto, Xavier cita André Bazin, que afirma que os limites da tela não são os quadros, como normalmente se define, mas sim os "recortes" que mostram somente uma parte do real à sua frente (XAVIER, 2005, p. 21). A ideia de recorte é reforçada pelo próprio movimento da câmera, que, ao recortar uma parte num dado instante, apresenta outras partes do todo com seu movimento, mas não todo o espaço: o movimento ainda é um recorte. Avanços e recuos, movimentos horizontais e verticais acabam, afinal, por omitir coisas em virtude de outras.

Para reforçar tal potencial linguístico/ideológico de um filme, Xavier demonstra a diferença entre uma tela de pintura e uma de cinema. Numa pintura o retângulo da imagem é visto como uma espécie de janela que se abre para um universo que existe em si e por si, embora separado do nosso mundo pela superfície da tela - uma espécie de vidro que nos separa tatilmente, mas não visualmente. Nesse aspecto, uma pintura apresenta-se como um microcosmo radicalmente separado do mundo real, embora tão próximo. Essa materialidade artística é uma composição contida dentro dela mesma, com regras próprias. Apesar de contar sobre a realidade com mais intensidade do que a própria realidade, não tem nenhuma conexão imediata com o real: porque representa o real é que está separada dele, não pode ser a continuação do mundo (XAVIER, 2005).

Para a corrente cinematográfica naturalista, aponta Xavier, a imagem cinematográfica é "real" (como se omitisse a etapa da 
representação), o que impele o cinema a tentar fazer com que seus elementos técnicos de construção pareçam "naturais". De fato, outras correntes tomaram emprestados especificamente esses conceitos do Naturalismo, ou seja, esta busca pela naturalização dos elementos da linguagem cinematográfica, de modo que todos eles se tornem imperceptíveis para o espectador, o que aumentaria o efeito de realidade produzido pela obra fílmica. Todos os elementos devem ser naturais: a interpretação dos atores, os planos, os ângulos, os movimentos de câmera, os efeitos especiais etc. Por mais inverossímeis que sejam as ações transcorridas, tais valores do cinema intentam uma reprodução fiel das aparências imediatas do mundo empírico, uma afirmação da ilusão de que o espectador está em relação direta com o universo representado, sem intervenções, "como se todos os aparatos de linguagem utilizados constituíssem um dispositivo transparente, o discurso como natureza" (XAVIER, 2005, p. 43).

O modelo naturalista representa uma convergência radical entre a construção de um discurso que se quer transparente (efeito de janela/fluência narrativa) e a modelagem precisa de uma dupla máscara: para propor uma ideologia como verdade, tal máscara insinua-se na superfície da tela (produzindo os efeitos ilusionistas) e insinua-se, na profundidade e na duração produzidas por estes efeitos, produzindo as convenções do universo imaginário no qual o espectador mergulha (XAVIER, 2005, p. 46).

Porém, a janela cinematográfica, ao abrir para o mundo, possui forças que outras artes não possuem: subverte aquela segregação física e carrega o espectador para o interior da tela, cria a ilusão de que ele está no "interior da ação reproduzida no espaço ficcional do filme" (BALAZS, 1970, p. 50). Esse efeito aliciador do cinema tem grandes implicações para a Análise do Discurso. Para Pêcheux, "o lugar de onde se fala" também fala (apud ORLANDI, 
2005, p. 39). Certa aproximação conceitual se faz possível (ainda que com cuidado e ressalvas) entre o conceito de "assujeitamento", em Pêcheux, com o que Xavier, citando Edgar Morin, chama de processo de "Identificação/Projeção". Nesse processo, o cinema se dá como constituição de um mundo imaginário que vem transformarse no lugar por excelência de manifestação dos desejos, sonhos e mitos do homem que, segundo Morin, se dão pela convergência entre as características da imagem cinematográfica e determinadas estruturas mentais de base. Assim, a identificação constitui a alma do cinema na medida em que materializa aquilo que a vida real não pode satisfazer. O cinema, portanto, é o antropomorfo ideal, ou seja, aquilo que, apesar de não ser humano, parece carregar em si nossas características mais ontológicas, como se fosse um de nós, contudo ampliado, melhorado, com mais ação, aventuras e finais felizes.

Assim, sob os efeitos da ideologia, esses mecanismos cinematográficos fazem parecer natural o aparecimento de apenas um sentido nos filmes, documentários, textualizações midiáticas etc, marcando um impedimento para o sujeito conjeturar que os sentidos poderiam ser outros, diversos daqueles que se estabelecem como dominantes ou já legitimados. Tal como a ciência, o cinema instrumentaliza o "natural" através de técnicas materiais que dirigem a realidade rumo a efeitos "procurados" (PÊCHEUX, 2008, p. 31).

Dessa aproximação conceitual entre o "processo de identificação/projeção", de Morin, comoconceitode "assujeitamento ideológico", de Pêcheux, emergem evidências de que o discurso cinematográfico faz circular uma suposta coincidência entre os atos de linguagem e os supostos fatos puros, instalando o mote da transparência e da univocidade, como se não existissem outros modos de dizer, relatar, contar, narrar fatos. Dessa forma, apagamse os enunciados dos e sobre os equívocos - fissuras, sabotando a possibilidade de que a imprecisão, a inexatidão, os não-ditos e o silenciamento possam ser falados (PÊCHEUX; FUCHS, 1997). E será dentro dessa univocidade que o sujeito tomará contato com o 
discurso de um filme, constituindo sentidos e o próprio sujeito; ou como diz o "processo de identificação/projeção": sujeito e filme se identificam num alto grau de antropomorfia, projetando e instalando realidades unívocas e conclusas (XAVIER, 2005, p. 24).

Vê-se, portanto, que até as constituições internas do cinema (suas condições técnicas de produção) já reforçam o imaginário de que existe uma correspondência, termo a termo, entre as cenas e o mundo, entre os relatos e os "fatos". Visto dessa forma, o discurso cinematográfico reforça o lugar supostamente constituído pela ausência de sombras, em que as sequências de cenas ratificam os acontecimentos, em que os relatos correspondem à verdade pura e em que um poder está permanentemente funcionando como uma credencial simbólica de verdade.

Retomando o conceito de "Formações Imaginárias" (PÊCHEUX; FUCHS, 1997, p. 82) para essa discussão sobre os mecanismos discursivos intrínsecos do cinema, vemos na relação cinema/espectador duas posições em situação de assimetria: a primeira ocupa um lugar de poder, ou melhor, do poder de narrar a realidade com palavras sem sombras; ao segundo cabe o lugar, antecipadamente imaginado, de espectador consumidor, crédulo, voraz e necessitado de informações, que está sempre prestes a recebê-las, em qualquer tempo e lugar, em um fluxo contínuo de informação que não pode ser interrompido.

Ao saber-e-poder-a-mais (BUCCI; KEHL, 2004) da mídia (cinema) corresponde um suposto saber-e-poder-a-menos do espectador, combinando as seguintes imagens: à primeira está dada a potência de traçar relatos, escolher o que merece ser narrado, selecionar os fatos tidos como meritórios de destaque e fazê-los circular nas salas de cinema ao redor do mundo. E, à segunda imagem, cabe o papel de consumidor de um universo de informações que lhe moldam desejos e necessidades sempre perseguidas, que materializa aquilo que a vida "real" não pode satisfazer.

Concluímos este tópico enfatizando as evidências de que os próprios mecanismos de construção do cinema se apresentam 
como ferramentas ideológicas nas mãos do diretor cinematográfico, que, afinal, pode (ou não) fazer trabalhar um único sentido como sendo "verdadeiro". O diretor, como se sabe, depende de agências de fomento ou investidores privados, de atores políticos e mercadológicos para uma boa distribuição, além de outras relações comerciais para que seu filme alcance grande bilheteria. Essas filiações políticas e ideológicas evidenciam, portanto, as Formações Ideológicas e Discursivas a que se submete um determinado filme. E marcam, consequentemente, os efeitos de sentidos utilizados pela Técnica Cinematográfica empregada: os silenciamentos do recorte da câmera, a desambiguação e univocidade sugerida pela linearidade temporal construída no filme, movimentos de assujeitamento segundo uma ou outra filiação ideológica e muito mais, como veremos adiante.

\section{A decupagem e a montagem cinematográfica como ferramentas discursivas}

Nesta seção do artigo, traçaremos uma discussão sobre a decupagem cinematográfica, que pressupõe, classicamente, que um filme seja constituído por sequências menores, cada uma com sua função dramática específica. Cada sequência é, ainda, constituída por cenas ainda menores que, somadas, compõem uma unidade espaço-temporal. Assim, decupagem é o processo de decomposição do filme (sequências e cenas) até chegarmos a cada plano, que é um recorte que a lente faz do mundo (XAVIER, 2005).

O plano, no entanto, corresponde a um determinado ponto de vista em relação ao objeto filmado, ponto de vista este que é manipulado pelos diversos tipos de movimentos e enquadramentos da câmera. Assim, cada plano já classificado e legitimado no cinema trabalha na condução do olhar do espectador e na constituição de ênfases, ritmo, composição, ocultamentos etc. Assim, plano geral, plano médio, plano americano, primeiro plano, além de 
seus movimentos zoom in, zoom out, fade in, fade out e outros (XAVIER, 2005) são recursos técnicos intrínsecos ao cinema na construção da narrativa. Cada movimento de câmera "fala", cada enquadramento discursiviza. Cada plano enfatiza enquanto oculta, fala enquanto silencia. Cada movimento de câmera constrói certo ritmo na sequência de cenas que causa um efeito discursivo diferente. Todos os mecanismos de decupagem falam, mas falam com um poder de discursividade nunca imaginado. Sua "antropomorfose" é impressionante: simula o olhar humano que, curioso, olha mais atentamente para um objeto em detrimento de outros, que se move em busca de algo que corre, que percebe um movimento e antecipa outros. Soma-se a isso uma sonoridade também intrínseca, com efeitos semelhantes aos imagéticos: cada pequeno ruído é constituinte daquele discurso. Todavia, no cinema, é a câmera que tem curiosidade pelo espectador: é ela quem antecipa os movimentos, que direciona os olhares, que diz o que é mais relevante. No filme, os sons do mundo são manipulados e instrumentalizados segundo uma necessidade discursiva hermética. Assim, enquanto cria uma poderosa identificação do sujeito espectador com o microcosmo "além-tela", assujeita o olhar do espectador e o conduz a pensar exatamente o que a câmera escolhe olhar e de que forma olha e escuta. Através desses recursos cinematográficos, ampliam-se as sensações dramáticas: o suspense, o medo, o sorriso, a satisfação etc, são potencializados nessa soma de atuação (a encenação que devidamente ocorre), efeitos de decupagem e sonografia (XAVIER, 2005).

Os recursos discursivos intrínsecos ao Cinema Naturalista ainda não foram amplamente descritos. Nos falta estudar um efeito cinematográfico de enorme importância para esta discussão: a montagem. No teatro, duas cenas são separadas por um intervalo para a preparação do novo cenário, no entanto, mesmo separadas, as cenas contam uma única história: somadas elas falam, cada qual uma enunciação, uma única grande fala. Contudo, no Cinema Naturalista a montagem suprime esse tempo de espera entre uma 
cena e outra, e até mesmo a distância entre um espaço e outro. Inicialmente, os filmes possuíam cenas longas, e os espaços dramáticos eram maiores. Hoje é possível uma cena no Japão que rapidamente se desloca para outra na Austrália, quiçá, numa mesma cena, uma parte do cenário pode estar até mesmo num continente diferente. É possível concatenar qualquer evento inverossímil a outros ainda mais contingentes e fazê-los parecer lineares, naturais e reais.

As regras de continuidade fazem funcionar uma combinação de planos, que resulta numa sequência fluente de imagens que gradativamente dissolve a descontinuidade visual elementar: reconstrói-se uma continuidade espaço-temporal a partir de fragmentos que não possuem relação natural alguma entre eles. A decupagem, usando a montagem, possui uma premissa constitutiva que estabelece uma lógica entre os fatos, relacionando fenômenos justapostos, todavia, buscando uma neutralização da descontinuidade elementar, ou seja, dotando de transparência o efeito da montagem (XAVIER, 2005). A realidade natural do mundo é perseguida mesmo nas mais absurdas tramas fantasiosas, e o ideal perseguido é o da plenitude de coerência na evolução dos movimentos ainda em sua dimensão física. Cada pequeno fragmento de cena é manipulado conferindo uma ordem narrativa e discursiva que manipula a atenção do espectador.

A crítica imanente na obra de Ismail Xavier é sobre o que se dá com o sujeito no final de uma sessão de Cinema Naturalista. Os elementos cinematográficos mais básicos e constitutivos, usados com o intuito de alcançar o naturalismo e o realismo, podem ser efêmeros; contudo, naquela sessão de cinema ideias foram trabalhadas e discursivizadas num altíssimo nível de identificação. $\mathrm{O}$ cinema é uma realidade criada e controlada por imagens: tudo cronometrado, composto e previsto. Todo o "visível" acontece enquanto se trabalha outra força inversamente proporcional de invisibilidade dos meios de produção dessa realidade: um sistema de representação da realidade que procura anular a própria presença 
enquanto força ordenadora dessa representação, conferindo à representação cinematográfica não um caráter de simulação distorcida, mas sim uma representação fiel do mundo (XAVIER, 2005). Tal reprodução da realidade funciona como instrumento retórico.

A reconstrução desse mundo (cópia) é feita com muito cuidado e zelo, com certo respeito à verdade, que por sua vez tende a ser creditada ao filme. É como uma pedra escura mergulhada em tinta branca: o filme surreal, ao passar pelo manto de tinta branca da "realidade", se reveste dela sem a ser (XAVIER, 2005). Xavier aponta que o problema da produção hollywoodiana não está somente em que se fabricam realidades, mas também no próprio método desta fabricação, ou melhor, nas articulações desses procedimentos com os interesses ideológicos que guiam tais produções (XAVIER, 2005). Enquanto a decupagem orienta, constrói e condiciona olhares e dizeres, ela se esconde, dissimula a própria existência justamente para que a linearidade e a "realidade" cinematográfica possam tomar seu lugar central no filme. E é justamente essa "transparência" que faz parecer que a origem daqueles sentidos é o próprio sujeito, que aqueles dizeres foram captados e compreendidos tal como foram justamente porque o sujeito parece ser a causa de si mesmo. Se parece que não foi o estado, nem as grandes corporações capitalistas, nem os diretores de cinema que disseram o que foi dito, então parece que foi o sujeito mesmo quem disse, uma "fantasia metafísica" (PÊCHEUX, 1995, p. 157) que coloca o sujeito do discurso como origem de si mesmo.

\section{Enquanto a câmera fala, o Diabo veste Prada: uma breve análise}

De toda produção cinematográfica, de milhares de cenas e produções, tomamos como corpus de análise para este texto um fragmento do longa-metragem "O Diabo veste Prada" (2006). 
Poderíamos nos deter a analisar cenas incríveis de ficções científicas, que conseguem, através da decupagem, trabalhar o impossível como se fosse natural. Porém, nos deteremos a apresentar um conjunto de cenas aparentemente mais críveis - sem deixar de serem impossíveis, o que evidencia o que até então discutimos. Nesse corpus de análise será possível dotar de opacidade o processo de decupagem como ferramenta discursiva, ou seja, como um conjunto de recursos de filmagem e montagem que são, eles mesmos, elementos discursivos dentro da linguagem cinematográfica.

Faz-se importante trazer, ainda que brevemente, uma breve descrição da trama do filme O Diabo Veste Prada. Andy (Anne Hataway), uma recém-formada jornalista, é aprovada numa entrevista para ser assistente de Miranda Priestly (Meryl Streep), a poderosa editora-chefe da revista Runaway. O que seria uma vitória aos poucos começa a se mostrar um grande desafio, já que passa a sofrer muito preconceito e violência moral no trabalho, tanto pela editora-chefe quanto pelas colegas de trabalho. Até que ela resolve mudar de postura e se entregar aos saberes da moda. Ela começa então a crescer profissionalmente enquanto se afasta de amigos, familiares e do namorado, até que rompem o relacionamento. Ela passa a ficar horas intermináveis no trabalho e aceita uma proposta antiética de Miranda para sua ascensão profissional. No final, a editora-chefe, para continuar no topo do mundo da moda, prejudica gravemente um amigo. Andy se recusa a continuar nesta direção, que culminaria em transformá-la numa outra Miranda Priestly, e vai à procura de outro emprego.

Faremos, portanto, alguns recortes na intenção de captar pistas discursivas que evidenciem o poder do Cinema Naturalista e da Decupagem Clássica em construir ilusões que fazem concatenações impossíveis de eventos parecerem cenas aparentemente normais. Mais que isso, buscaremos evidenciar como esses recursos cinematográficos/discursivos enunciam e constroem sentidos.

Andy, por ser uma recém-contratada jornalista que consegue um trabalho numa grande revista de moda, ainda é desprovida dos 
saberes necessários para cumprir sua função, além de estar alheia aos jogos de linguagem comuns ao meio. Uma importante pista discursiva que pinçaremos surge das longas cenas iniciais em que Andy aparece com a mesma roupa: um suéter azul e uma saia considerada obsoleta para os padrões da moda.

Ela assume, até então, uma posição desprovida dos saberes da moda, logo, despreparada para as atualizações típicas deste universo; seus dizeres e saberes acerca da moda estão estagnados, manifestos em suas roupas. Aquele mesmo suéter azul, vestido por ela durante boa parte do filme, evidencia uma nítida resistência aos saberes estilísticos da moda. Andy manifesta essa resistência também através de certo tripúdio aos excessivos nomes de adereços e cores do mundo fashionista, como na cena em que sua chefe, Miranda, lhe diz duras palavras acerca de seu descaso e ignorância sobre esses dizeres tão importantes para a moda. Vale notar que o ritmo dessas cenas iniciais é marcado pela lentidão nos cortes e planos, até mesmo nas falas dos atores, em seus movimentos e na trilha sonora, acompanhando, de certa forma, a lentidão fashionista de Andy.

Figura 1: O que é aquilo que ela está vestindo?

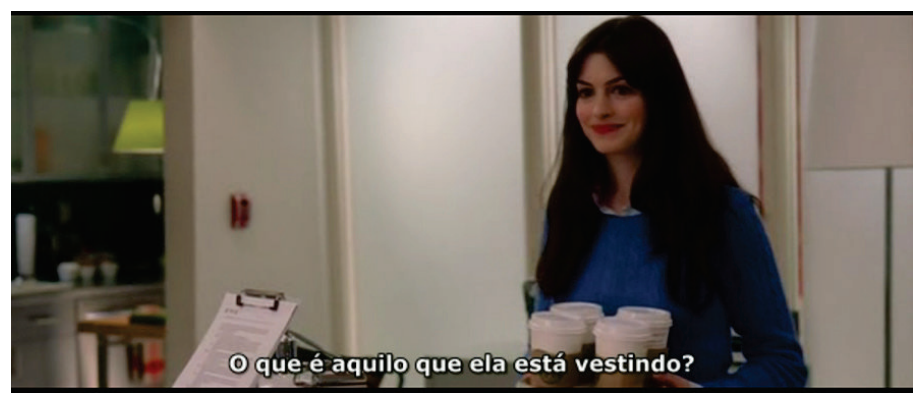

Fonte: O Diabo veste Prada (2006).

Contudo, se até então sua posição-sujeito era atrasada, inadequada e insuficiente dentro dos emaranhados dizeres da moda, 
num dado instante do filme Andy começa a sofrer abusos de todas as ordens (morais, profissionais etc), justamente por não se adequar ao ritmo alucinante da moda. Novamente é possível verificar a lentidão das cenas em que Andy evidencia sua inadequação e resistência para com as mudanças.

Figura 2 : Trapos

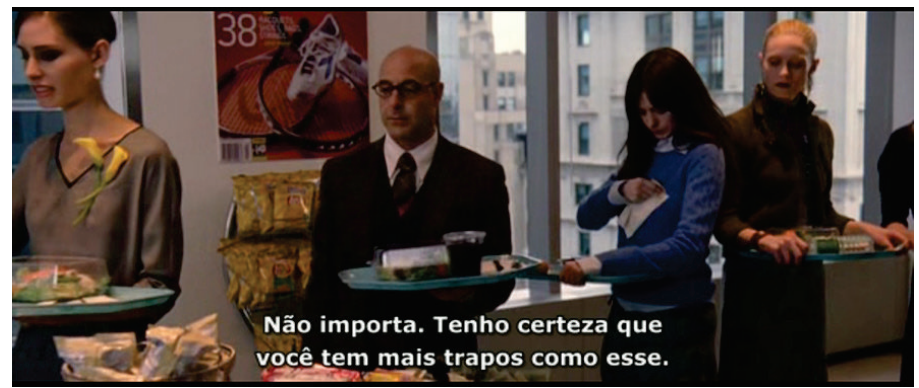

Fonte: O Diabo veste Prada (2006).

A inadequação de Andy para com o ritmo da moda é acompanhada, como já fora dito, por certa resistência de sua parte, além de certa justificativa fundamentada numa crença de futilidade da moda.

Figura 3: Mudar o jeito

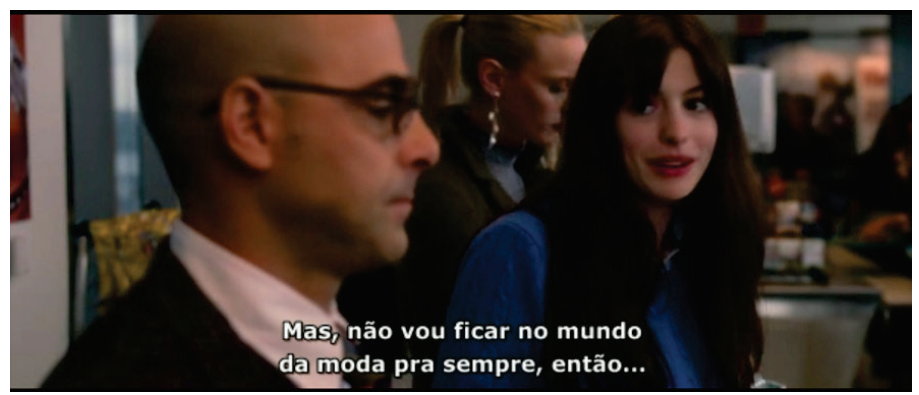

Fonte: O Diabo veste Prada (2006). 
Figura 4: Ainda sobre mudar o jeito

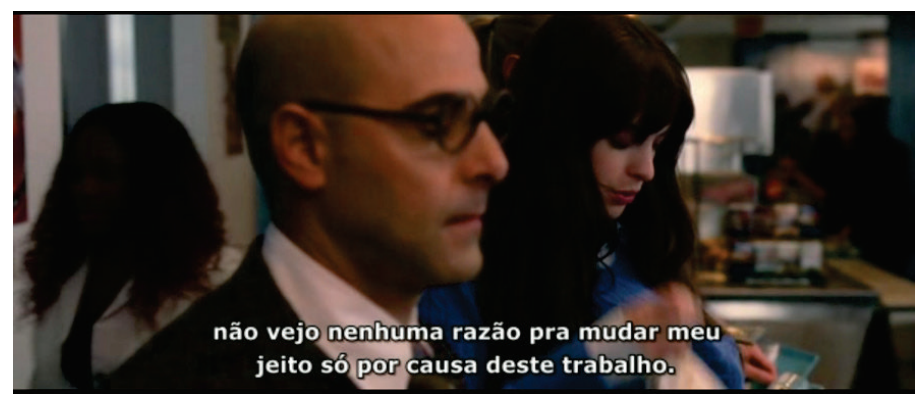

Fonte: O Diabo veste Prada (2006).

Diante da hostilidade de todos, e da iminência de perder o emprego, Andy decide aprender os saberes sobre a moda e jogar o jogo que lhe era imposto, o que implicaria vestir-se de forma adequada para aquela função. Essa mudança de atitude marca, no filme, uma mudança de ritmos, trilhas, montagens, recortes, campos e de toda estrutura por trás das câmeras: quase um novo filme. É neste contexto da trama que o filme apresenta uma importante sequência de planos que revela o poder ilusionista e discursivo da Decupagem Clássica. Nessa cena, um complexo e incrível encadeamento de planos faz trabalhar um importante sentido para esta discussão, qual seja, o da velocidade da moda. Vamos às cenas.

No percurso de casa até o trabalho, depois da virada radical de sua posição, Andy aparece com várias composições de roupas diferentes, no entanto, todas elas devidamente atualizadas no tempo da moda. Vejamos a montagem que encadeia essa "mudança no estilo de roupas", contudo, uma mudança no sentido de "várias mudanças". O velho estilo de Andy parecia ser lento, mas agora seu novo estilo, além de novo, é rápido em se transmutar. 
Figura 5: Andy sai de casa com sua nova roupa.

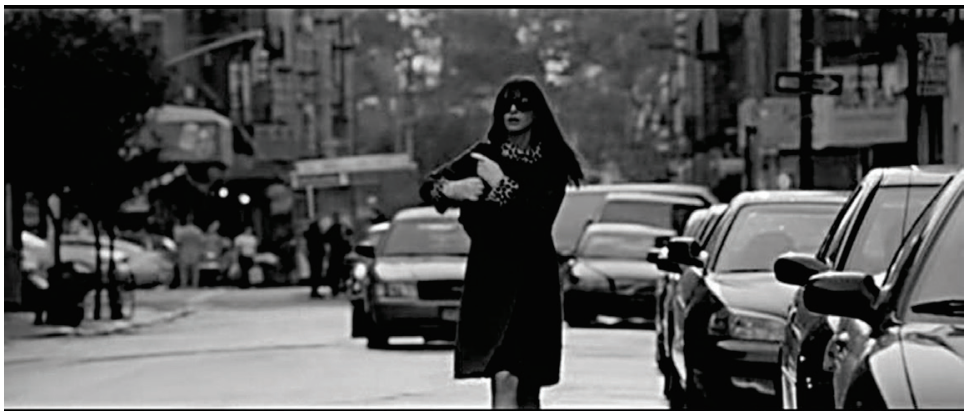

Fonte: O Diabo veste Prada (2006).

Figura 6: Ela entra no metrô e sai com outra roupa.

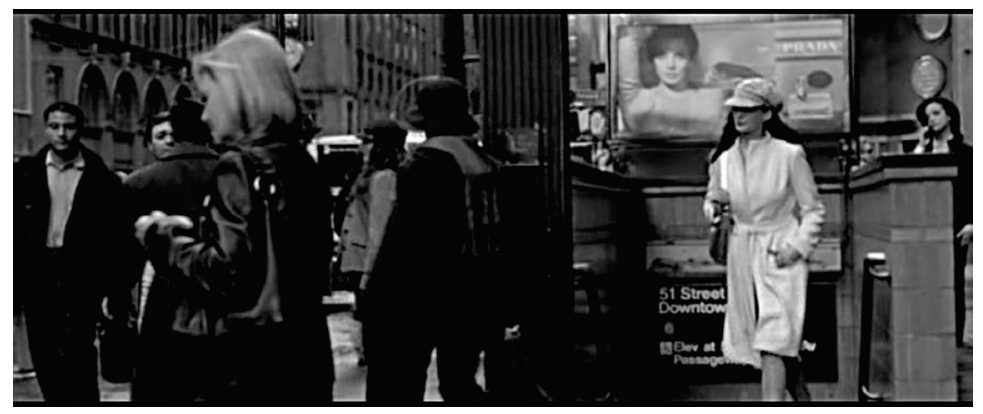

Fonte: O Diabo veste Prada (2006).

Figura 7: Um carro passa entre ela e a câmera, e novamente ela aparece com outra roupa.

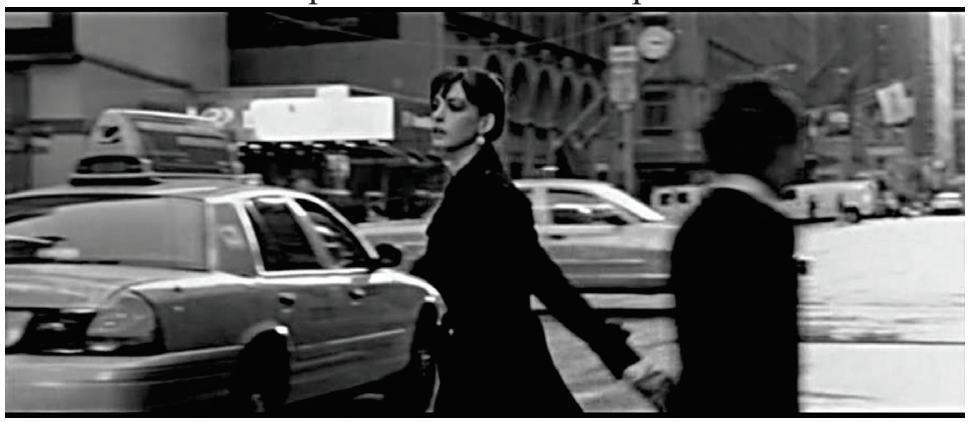


Fonte: O Diabo veste Prada (2006).

Essa cena possui exatos quarenta segundos, e nela Andy aparece com seis roupas diferentes. Se até então seu suéter azul era sua única vestimenta, agora, pelas vias da decupagem, o filme contrapõe o velho e lento com o novo e ágil. Os cortes são rápidos, e a montagem faz funcionar uma linearidade temporal absurda, que no final se naturaliza. No simples trajeto de sua casa ao trabalho Andy troca várias vezes de roupa, o que dá impressão temporal de que se trata de um único dia, e não de vários, de que as mudanças são rápidas, dinâmicas e agradáveis, justamente o oposto da letargia pragmática em que constituía dentro do campo da moda. Nessa cena, entre um metrô, um táxi e uma caminhada, suas roupas são alteradas numa concatenação temporal nitidamente não linear, mas linearizada de forma a compor uma única relação de espaço e tempo. Na velocidade de uma passagem de um carro, ou entre uma coluna e outra de um edifício, enquanto passa por elas, Andy muda.

Há, nessa cena, uma nítida quebra na continuidade temporal: ações que levariam dias para acontecerem são realizadas em quarenta segundos, encadeadas temporalmente de forma a trabalhar e naturalizar um sentido de "agilidade" e "novidade". A Decupagem Clássica, através da montagem, concatena espaços, momentos, pessoas e situações distintas e distantes; mas nesse caso, não de forma imperceptível. Nessa cena de O Diabo veste Prada vê-se um encadeamento de planos que possuem, afinal, um claro movimento discursivo que fala em prol do novo em detrimento do obsoleto. A dinâmica da decupagem se transforma, e desta cena em diante tudo se torna mais ágil no filme: a trilha sonora torna-se mais alegre, ares de mudança e progresso parecem envolver a protagonista do filme, mas tudo isso se dá de forma implícita na estrutura do próprio filme, uma vez que é a decupagem e a montagem que operam dizeres de forma fictícia, artificial e, nesse caso, hiperbólica. 


\section{Conclusão}

Como conclusão queremos nos ater para a evidência de que a própria câmera fala; seu enquadramento, seus movimentos e olhares direcionados, enfim, mostram-se poderosas e eficientes ferramentas discursivas. A própria decupagem cinematográfica fala ao mesmo tempo em que tenta apagar sua presença enquanto elemento discursivo, sugerindo uma voz natural, como se não houvesse outra forma de falar e capturar aquele sentido; sugere, enfim, que o sujeito está na origem dos sentidos e do próprio sujeito.

Se falamos de ideologia, manipulação e naturalização de sentidos discursivos no cinema, fica evidente a filiação ideológica do filme O Diabo veste Prada, uma vez que sua produção e divulgação se dão imersas numa ideologia que assujeita o cidadão ocidental numa perene competição por uma posição de destaque. E neste caso, o pecado maior é ser visto com um objeto obsoleto, uma roupa obsoleta, uma ideia obsoleta: elementos obsoletos que envelhecem o próprio sujeito. E para tanto, para estar apto a ocupar um lugar discursivo de destaque, deve-se estar disposto a abrir mão de qualquer coisa que o vincule ao passado, que lhe impeça de correr livremente em direção ao novo, ao futuro, ao sucesso. A ordem do dia é a mudança, é estar livre para mudar e evoluir. Estas são as novas regras do jogo manifestas não só nos dizeres explícitos deste filme, mas também em sua constituição por trás das câmeras.

A Decupagem Clássica, como analisada neste filme, trabalha sentidos discursivos ideologicamente estabelecidos no mesmo instante em que tenta apagar a própria atuação, fazendo parecer que, tal como no filme, a vida deve ser rápida, ágil, pronta para as mudanças e adaptações que a moda e o capitalismo exigem. Ora, se o filme retrata o cotidiano de forma natural, as regras, os dizeres e os sentidos propostos pelo filme devem ser acolhidos de forma inequívoca e estável. Este, portanto, é o principal problema ético a que podemos lançar luz a partir dos pensadores trabalhados neste artigo (Michel Pêcheux e Ismail Xavier): a capacidade do 
Cinema Naturalista em trabalhar a ilusão da continuidade como uma poderosa ferramenta ideológica e discursiva.

\section{Referências}

BALAZS, Bela. Theory of the film. Nova York: Dover Public. Inc, 1970.

BUCCI, Eugênio; KEHL, Maria Rita. Videologias. São Paulo: Boitempo Editorial, 2004.

ORLANDI, Eni. As formas do silêncio: no movimento dos sentidos. Campinas: Ed. Unicamp, 1997.

Análise de Discurso: princípios e procedimentos. Campinas: Pontes, 2005.

PÊCHEUX, Michel; FUCHS, Catherine. Por uma análise automática do discurso: uma introdução à obra de Michel Pecheux. Tradução Bethania Mariani, et al. Organizadores Francaise Gadet, Tony Hak. Campinas: Unicamp, 1997.

PÊCHEUX, Michel. Semântica e discurso: uma crítica à afirmação do óbvio. $2^{a}$ ed. Campinas: Editora da Unicamp, 1995.

. O discurso: estrutura ou acontecimento. Campinas: Pontes Editores, 2008.

XAVIER, Ismail. O discurso cinematográfico: a opacidade e a transparência. São Paulo: Paz e Terra, 2005. 


\section{Filmografia}

O DIABO veste Prada. Direção: David Frankel. [Leg.]: Wendy Finerman, 2006. 1 DVD (110 min), NTSC, color. Título original: The Devil wears Prada. 